\title{
Comparison between Elastic and Inelastic Lateral Torsional Buckling Load on Circular Fixed Channel Section Arches under Transverse Point Load
}

\author{
Emmanuel-Peters Teke Tebo*, Leonard Masu ${ }^{1}$ and Patrick Nziu ${ }^{2}$ \\ *Department of mechanical engineering, Vaal University of Technology, Andries Potgieter Blvd, Vanderbijlpark, 1900, Gauteng, \\ South Africa. \\ ${ }^{1}$ Department of mechanical engineering, Vaal University of Technology, Andries Potgieter Blvd, Vanderbijlpark, 1900, Gauteng, \\ South Africa. \\ ${ }^{2}$ Department of mechanical engineering, Vaal University of Technology, Andries Potgieter Blvd, Vanderbijlpark, 1900, Gauteng, \\ South Africa.
}

ORCIDs: 0000-0003-4926-8828 (Emmanuel-Peters Teke Tebo), 0000-0002-8544-6321 (Leonard Masu), 0000-0002-5899-0700(Patrick Nziu)

\begin{abstract}
This paper presents a Finite Element Analysis (FEA) investigation on the elastic and inelastic prebuckling behaviour and Lateral-Torsional Buckling (LTB) loads on circular fixed ends arches of 6061-T6 aluminium alloy channel sections subjected to a transverse point load at the shear centre. The software package Abaqus was used to study a total of 110 arch models from three separate channel sections with an additional 16 arch models for validation. From the channel arches, 66 were developed at a constant length, while the remaining 44 arches were formed at constant slender ratios using 11 discrete included angles. The analytical and FEA prebuckling results showed good agreement, indicating that the FE models were reliable, efficient, and accurate. From this comparison, the elastic axial compressive forces were found to be higher than those of inelastic prebuckling ones and the opposite was true for the bending moments. For arches developed at constant span length, the maximum elastic LTB load overestimated the real LTB load by over 48 percent and decreases as the web to flange width ratio increases. Furthermore, the maximum elastic LTB load for arches developed constant slender ratio, $S / r_{x}=$ 60 overestimated its inelastic counterpart by 38.8 percent. While at $S / r_{x}=90$, the elastic LTB load overestimated its inelastic counterpart by only 14.1 percent. It was also found that as the slender ratio increased, the difference between the elastic and inelastic LTB loads drops and vice versa.
\end{abstract}

Keyword: circular fixed arches, elastic and inelastic, lateraltorsional buckling, shear centre, concentrated load, prebuckling, constant slender ratio and span length.

\section{INTRODUCTION}

The lateral-torsional buckling (LTB) of fixed end arches subjected to transverse point load or central concentrated load (CCL) has been researched on extensively ( $\mathrm{Liu}, \mathrm{Lu}, \mathrm{Fu} \& \mathrm{Pi}$
2017; Spoorenberg 2011; Tebo, Masu \& Nziu 2020). These existing studies could be categorised under the elastic and elastic-plastic also referred to as inelastic analysis (Spoorenberg 2011). However, most of the related studies focused on the elastic analysis (Liu et al. 2017; Spoorenberg, Snijder, Hoenderkamp \& Beg 2012). This can be justified, firstly, by the non-uniform axial compressive force and bending moment with complicated distribution patterns produced by the applied load that makes LTB analysis generally difficult (Liu et al. 2017). Also, the inelastic analysis becomes even more complicated as it accounts for imperfections (Guo, Zhao, Pi, Andrew \& Dou 2015). These imperfections include material nonlinearity, geometric imperfection, and residual stresses.

In general, studies have shown that by not taking into account the imperfection parameters for elastic analysis, may or may not have any significant effects on the LTB load of arches (La Poutré, Spoorenberg, Snijder, \& Hoenderkamp 2013). In case of any significant effects, the elastic analysis may overestimate or underestimate the real LTB load (Pi \& Bradford 2003). Studies on circular fixed end arches under transverse point loads have shown the elastic analysis to overestimate the LTB load (Pi \& Trahair 2000; Pi \& Bradford 2003, 2005; Spoorenberg et al. 2012). Besides, existing studies have focused on double-symmetric steel and aluminium I-sections with more studies reported on steel (Pi \& Trahair 2000; Pi \& Bradford 2003; Spoorenberg 2011). This leaves monosymmetric cross-sections like channel sections with inadequate data.

The LTB behaviour of channel sections differ from double symmetric sections due to eccentric loading experienced in channel sections as their centre of gravity and shear centre do not coincide (Dahmani \& Drizi 2015). Thus, it is relatively essential for such sections to be investigated, given advantages the channel section offers, such as the member's high performance with minimum weight (Kim, Min \& Su 2000). It

\footnotetext{
* Corresponding Author.
} 
would also be of more importance of such investigation to be carried out on metals such as structural aluminium alloys due to their significant inadequate data under the LTB stability failure (Wang, Yuan, Shi \& Cheng 2012). Furthermore, due to various advantages associated with the use of aluminium alloys such as lightweight, good durability, recyclability, toughness and corrosion resistance, the aluminium alloy is justifiably defined as green metal (Efthymiou, Cöcen \& Ermolli 2010; Tebo et al 2020).

Therefore, this paper investigated the elastic and inelastic prebuckling behaviour and LTB load of circular fixed end arches from 6061-T6 structural aluminium channel section under transverse point load at the shear centre. Comparisons were then made between the obtained results to see by what percentage does the elastic LTB loads over or underestimate the inelastic LTB loads. The two sets of arches to be investigated include arches developed at constant span length using different parallel flange channel sections and those developed at constant slender ratios from a single channel section.

\section{METHODOLOGY}

\subsection{Cases studied}

Given aluminium alloys wide spread of application in structures, the precipitated (weak hardening) 6061-T6 Al alloy was ideal for this study (Wang et al. 2012). Three definite parallel flange channel sections of 6061-T6 with part numbers 16831, 16825, and 16045 were selected from the Aluminum Standard Profile Catalog by Hulamin Extrusions (2015). Due to the LTB failure mode investigated in this study, the different sections were selected within the class 1 and 2 categories reported by Mazzolani (2004). Also, the sections were selected such that they are highly susceptible to failure by LTB as described in La Poutré (2005) PhD research. The general overview channel cross-section is shown in Figure 1, and the detail description of the parameters for the different channel sections part numbers are presented in Table $\mathbf{1}$.
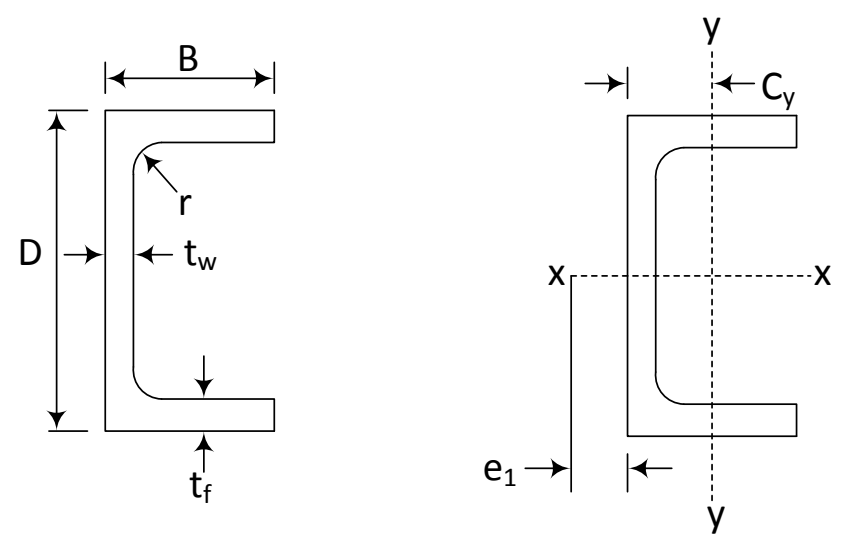

Figure 1: General cross-section of the aluminium alloy channel
Table 1: Detail description of the parallel flange channelsections studied in accordance with Figure 1 (Hulamin Extrusions, 2015)

\begin{tabular}{|l|l|c|c|c|}
\hline \multicolumn{2}{|l|}{ Part number } & 16045 & 16825 & 16831 \\
\hline \multicolumn{2}{|l|}{ Cross-section class } & 2 & 1 & 1 \\
\hline \multirow{2}{*}{ Web } & Height, $D(\mathrm{~mm})$ & 25.4 & 25.4 & 38.1 \\
\cline { 2 - 5 } & Thickness, $t_{w}(\mathrm{~mm})$ & 1.6 & 3.18 & 3.18 \\
\hline Range & Width, $B(\mathrm{~mm})$ & 12.7 & 12.7 & 12.7 \\
\cline { 2 - 5 } & Thickness, $t_{f}(\mathrm{~mm})$ & 1.6 & 3.18 & 3.18 \\
\hline Shear centre position, $e_{1}(\mathrm{~mm})$ & 3.6 & 2.5 & 2 \\
\hline $\begin{array}{l}\text { Centre of gravity position, } \\
C_{y}(\mathrm{~mm})\end{array}$ & 3.8 & 4.3 & 3.7 \\
\hline
\end{tabular}

The channel sections with part numbers 16045, 16825 and 16831 listed in Table $\mathbf{1}$ were used to develop the arches investigated in this study. The two main categories of arches investigated include those developed at constant span length, $L=500 \mathrm{~mm}$ and those developed at constant slender ratios, $S / r_{x}=60$ and 90 (where $S$ is the length of the arch and $r_{x}$ the radious of gyration). The schematic illustration of an arch with structural parameters is shown in Figure 2.

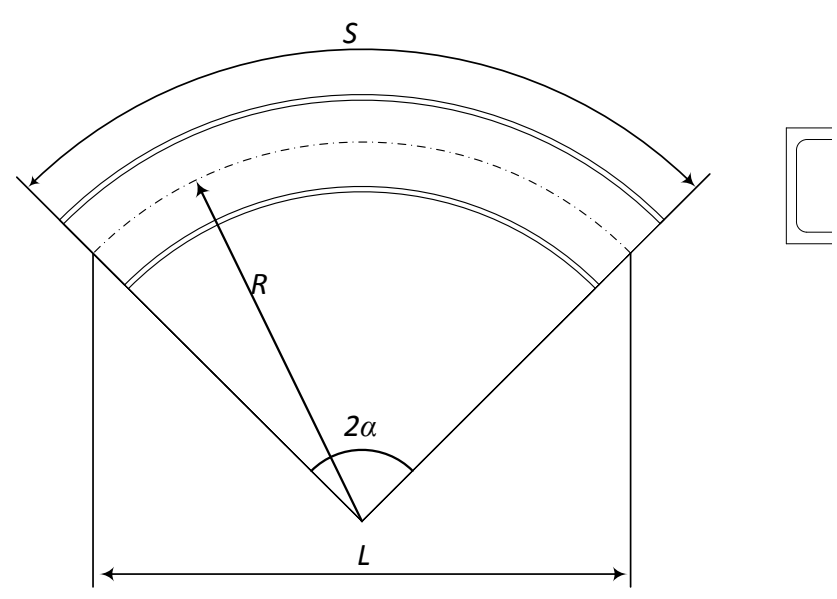

Figure 2: Structural representation of the arch model

Whereby, $R$ is the mean radius of the arc, $2 \alpha$ is the included angles.

\subsection{Numerical method}

The numerical technique considered in this study was the FEA due to its flexibility to perform elastic and inelastic analyses. Besides, the FEA procedure has been a more useful and accurate technique used by researchers to analyse the LTB of arches (Tebo et al. 2020). The stability analyses (ie linear elastic analysis (LEA), linear buckling analysis (LBA), material non-linear analysis (MNA), and geometrical material 
International Journal of Engineering Research and Technology. ISSN 0974-3154, Volume 13, Number 9 (2020), pp. 2239-2254

(C) International Research Publication House. https://dx.doi.org/10.37624/IJERT/13.9.2020.2239-2254

non-linear imperfection analysis (GMNIA)) were used in this study and are summarised in Table 2.

Table 2: Overview analysis types and incorporated issues

\begin{tabular}{|l|c|c|c|c|}
\hline Analysis type & \multicolumn{2}{|c|}{ Elastic } & \multicolumn{2}{c|}{ Inelastic } \\
\hline Issue & LEA & LBA & MNA & GMNIA \\
\hline $\begin{array}{l}\text { Equilibrium defined in } \\
\text { the undeformed state }\end{array}$ & $\mathrm{Y}$ & $\mathrm{N}$ & $\mathrm{Y}$ & $\mathrm{N}$ \\
\hline $\begin{array}{l}\text { Equilibrium define in } \\
\text { the deformed state }\end{array}$ & $\mathrm{N}$ & $\mathrm{Y}$ & $\mathrm{N}$ & $\mathrm{Y}$ \\
\hline $\begin{array}{l}\text { Significant rotation and } \\
\text { large strains }\end{array}$ & $\mathrm{N}$ & $\mathrm{N}$ & $\mathrm{N}$ & $\mathrm{Y}$ \\
\hline $\begin{array}{l}\text { Geometric } \\
\text { Imperfections }\end{array}$ & $\mathrm{N}$ & $\mathrm{N}$ & $\mathrm{N}$ & $\mathrm{Y}$ \\
\hline Residual stresses & $\mathrm{N}$ & $\mathrm{N}$ & $\mathrm{N}$ & $\mathrm{Y}$ \\
\hline Material nonlinearities & $\mathrm{N}$ & $\mathrm{N}$ & $\mathrm{Y}$ & $\mathrm{Y}$ \\
\hline Load multiplier & $\mathrm{N} / \mathrm{A}$ & $\beta_{c r}$ & $\beta_{p l}$ & $\beta_{u l t}$ \\
\hline
\end{tabular}

From Table 2, "Y" and "N" indicates issues taken and not taken into account, respectively, $\beta_{c r}, \beta_{p l}$, and $\beta_{u l t}$ are the elastic critical, in-plane plastic, and ultimate load coefficients of the arch, respectively. The LEA and MNA were used for prebuckling analyses to determine the axial compressive and bending actions. Whereas, the LBA was used to determine the eigenvalue, also referred to as the elastic buckling load, and GMNIA was used to determine the ultimate buckling load. Figure 3 summaries the modelling steps used for the elastic and inelastic analyses.

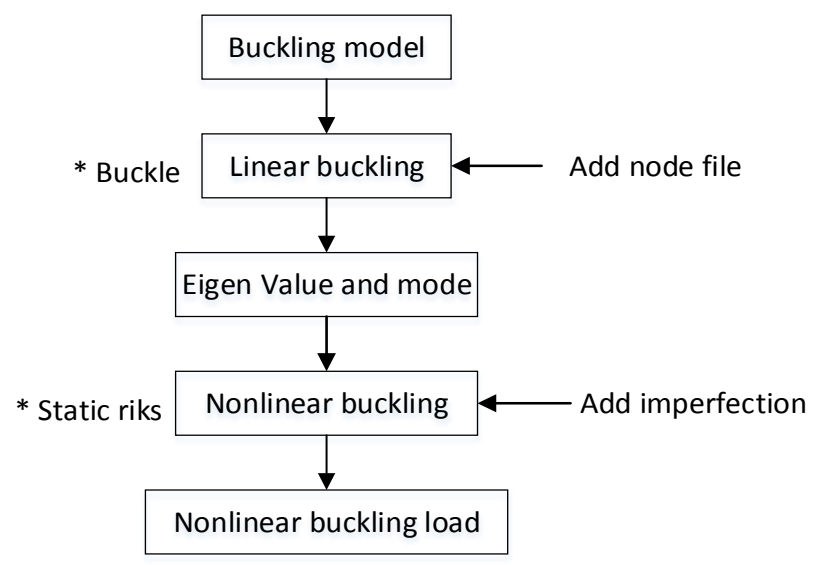

Figure 3: Summary of elastic and inelastic modelling in Abaqus

\subsubsection{Modelling}

3D commercial software Abaqus was used for the FEA since the software package could cover all the stability analyses outlined in Table 2.

For arches modelled at $L=500 \mathrm{~mm}$, a total of 66 models were developed with 11 distinctive arches formed from each part number outlined in Table $\mathbf{1}$ at separate included angles $(2 \alpha)$ in degrees. For elastic analyses, 33 models were used, while the remaining 33 were used for inelastic analyses. Meanwhile, for arches developed at $S / r_{x}=60$ and 90 , respectively, a total of 44 arch models where formed from part number 16025 using 11 distinctive included angles similar to arches developed at constant span length. That is; at $S / r_{x}=60$ a total of 22 arch models where developed, that is 11 elastic and 11 inelastic. The same applied for arches developed at $S / r_{x}=90$, given a total of 44 arch models. The distinctive investigated included angles include 5, 10, 15, 20, 30, 50, 70, 90, 120, 150 and 180 degrees.

\subsubsection{Part creation}

From the integrated modelling options in Abaqus, a 3D space, deformable type, with the basic characteristics of shell shape and sweeping design, was used to form arch models investigated in this study. A sample of the arch model created is shown in Figure 4.

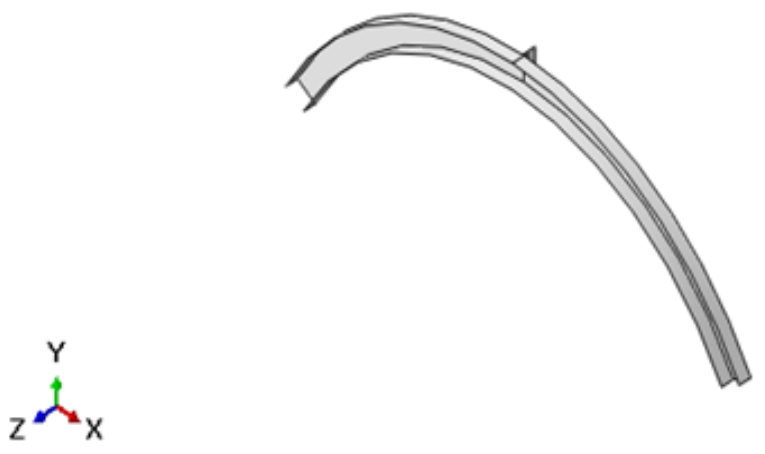

Figure 4: Part model

\subsubsection{Material properties}

Table 3 summaries the elastic and inelastic mechanical properties of 6061-T6 aluminium alloy of channel sections, that is; 16045,16825 and 16831.

Table 3: Material properties of aluminium alloy 6061-T6 (Aerospace Specification Metals Inc 2012) catalogue

\begin{tabular}{|c|c|c|c|}
\hline \multicolumn{2}{|c|}{$\begin{array}{c}\text { Elastic properties used } \\
\text { in Abaqus }\end{array}$} & \multicolumn{2}{|c|}{$\begin{array}{r}\text { Inelastic properties used in } \\
\text { Abaqus }\end{array}$} \\
\hline $\begin{array}{c}\text { Elastic } \\
\text { modulus, } \\
E(G P a)\end{array}$ & $\begin{array}{c}\text { Poisson's } \\
\text { ratio }\end{array}$ & $\begin{array}{c}\text { Tensile yield } \\
\text { strength, } f_{y} \\
(G P a)\end{array}$ & $\begin{array}{c}\text { Ultimate tensile } \\
\text { strength, } f_{\text {ult }} \\
(G P a)\end{array}$ \\
\hline 68.9 & 0.33 & 276 & 310 \\
\hline
\end{tabular}




\subsubsection{Load and boundary conditions}

The encastre boundary that provided no displacement and rotation in the $\mathrm{x}, \mathrm{y}$, and $\mathrm{z}$-directions (movement restriction either in-plane and out-of-plane at the supports) was used for both the elastic and inelastic analyses. While the load was applied downward in the y-direction at the shear centre using a welded plate twice the thickness of the web to avoid any deformation on the plate during LTB. Figure 5 presented the positions of the applied load and fixed support.

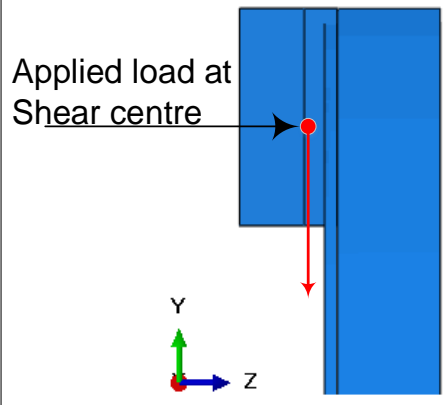

(A) Position of applied load

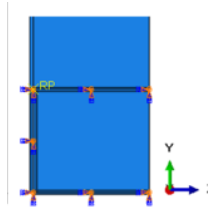

(B) Fixed support
Figure 5: Applied load and boundary condition

\subsubsection{The meshing of the model}

For a better comparison between the elastic and inelastic FE models, the same element type and mesh size was used for both analyses. A linear geometric order shell element, SR4 with three-dimensional, four-node, quadrilateral, stress/displacement doubly curved general-purpose shell element with six degrees of freedom at all nodes was used for the FE model. This SR4 shell element was selected since it provides accurate analysis results for thin-walled members and is suitable for analyses that involve finite membrane strains and large rotations (Valeš \& Stan 2017). Through mesh convergence, a global mesh size of $2 \mathrm{~mm}$ was adopted throughout the study. For profile 16825, the selected mesh size had six elements on the flange and eight elements on the web. Whereas for profile 16831, the flange had six elements and the web 13 elements, as shown in Figure 6.

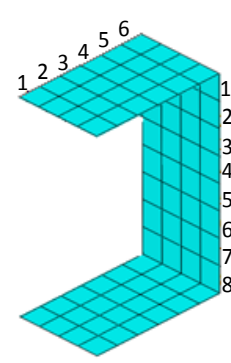

Profile 16825

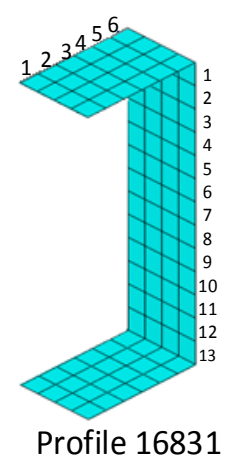

Profile 16831
Figure 6: Mesh size

\subsubsection{Imperfections}

As summarised in Table 2, the imperfections that are; material nonlinearity, geometric imperfection and residual stresses are only applicable for the non-linear analysis (inelastic). The bilinear elastic-plastic stress-strain curve that made use of the parameters $f_{y}$ and $f_{u l t}$ was used to apply the material nonlinearity. The maximum initial geometric imperfection $e=$ $S / 1000$ proposed by Spoorenberg (2011) $\mathrm{PhD}$ work for rolled bent arches was used for the geometric imperfection. Whereas, the residual stress model proposed by Snijder et al. (2008) for the channel section was employed to be the initial stress state of the arch models. In Abaqus, the residual stresses were applied at Gauss integrated points that corresponded with the centroid elements. A solution step using static general procedure was then carried out to check the force equilibrium in the cross-section using the normal stress S1, as shown in Figure 7.
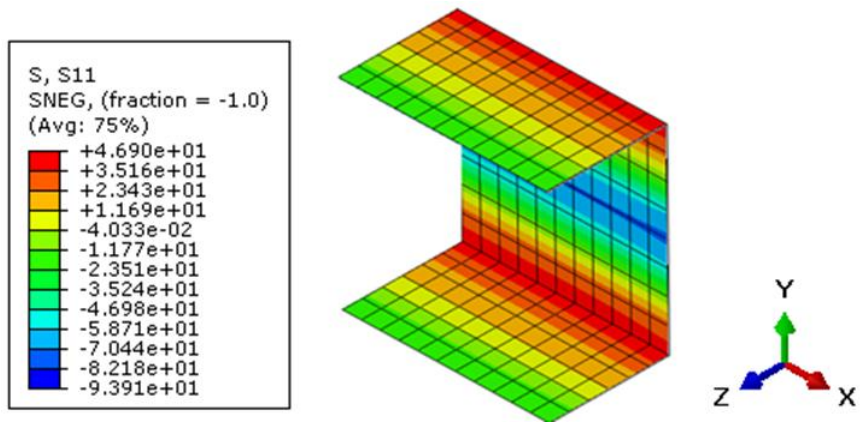

Figure 7: Representation of residual stress distribution in the FEA model

From Figure 7, it a coherence was noticed between the applied residual stress state and the initial stress state in the FE model, indicating the presence of internal equilibrium over the crosssections and the correct application of residual stresses in the models. Figure $\mathbf{8}$ then shows a schematic representation of the developed FE model in Abaqus.

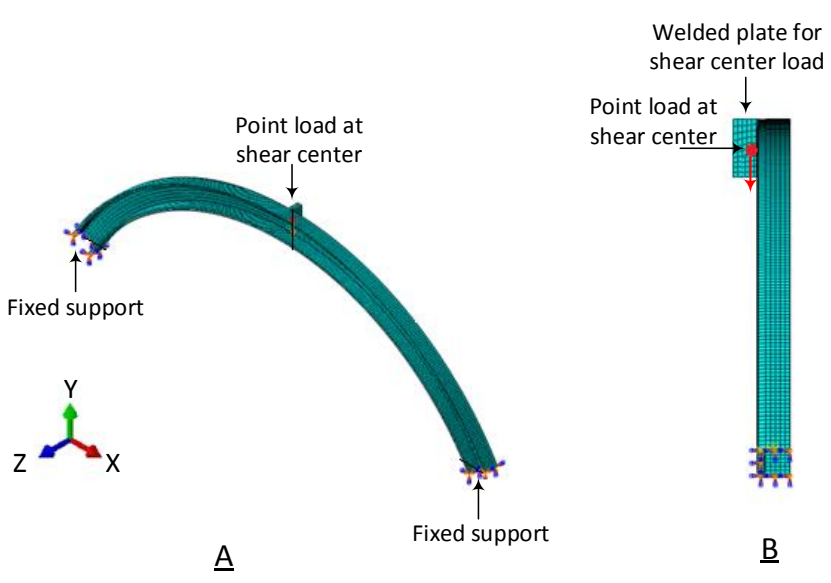

Figure 8: Practical representation of the arch model (A) isometric view (B) side view B 


\subsubsection{Solving phase}

The major analyses carried out were the LEA, LBA, MNA and GMNIA. The LEA was solved with the default static general procedure to determine the axial compressive forces $\left(N_{C}\right)$ and bending moment $\left(M_{C}\right)$ prior to buckling at the crown where their maximum values are expected based on existing studies (Pi \& Trahair 2000; Pi \& Bradford 2003; Pi et al. 2010). On the other hand, the LBA was used to determine the elastic LTB load, $F_{c r}$ and buckling behavior. The MNA and GMNIA used the Static Riks analysis technique in Abaqus. The Static Riks procedure was used because of its effectiveness in solving GMNIA problems and imperfection-sensitive systems as stated by Sadowski, Fajuyitan, and Wang (2017). The MNA was used to determine the inelastic axial compressive forces $\left(N_{m}\right)$ and bending moment $\left(M_{m}\right)$ at the crown. While the GMNIA was used to determine the ultimate buckling load $\left(F_{\text {ult }}\right)$.

\subsection{Validation of the finite element model}

The FE models developed using Abaqus, that is; both the elastic and inelastic models were validated using the existing analytical solutions proposed by Pi and Bradford (2003) and Liu et al. (2017). However, a double symmetric I-section was used to validate the exiting FE technique as the existing analytical solutions for fixed arches under point load were developed from the similar cross-section. Nevertheless, the same material properties, load and boundary conditions, element type and mesh size used for the investigated channel arches were applied on the validation FE model. Table 4 summaries the cross-section parameters of the validation model.

Table 4: Cross-section parameters for validation model

\begin{tabular}{|c|c|c|c|c|c|}
\hline \multicolumn{2}{|c|}{ Web } & \multicolumn{2}{|c|}{ Flange } & \multirow{2}{*}{$\begin{array}{c}\text { Load } \\
\text { position } \\
\text { from shear } \\
\text { centre, } y_{p} \\
(\mathrm{~mm})\end{array}$} & \multirow{2}{*}{$\begin{array}{c}\text { Arc } \\
\text { mean } \\
\text { radius, } \\
R(\mathrm{~mm})\end{array}$} \\
\hline $\begin{array}{l}\text { Height, } \\
D(\mathrm{~mm})\end{array}$ & $\begin{array}{l}\text { Thickness, } \\
t_{w}(\mathrm{~mm})\end{array}$ & $\begin{array}{c}\text { Width, } \\
B \\
(\mathrm{~mm})\end{array}$ & $\begin{array}{c}\text { Thickness, } \\
t_{f}(\mathrm{~mm})\end{array}$ & & \\
\hline 15.82 & 1.38 & 7.04 & 1.42 & -7.91 & 500 \\
\hline
\end{tabular}

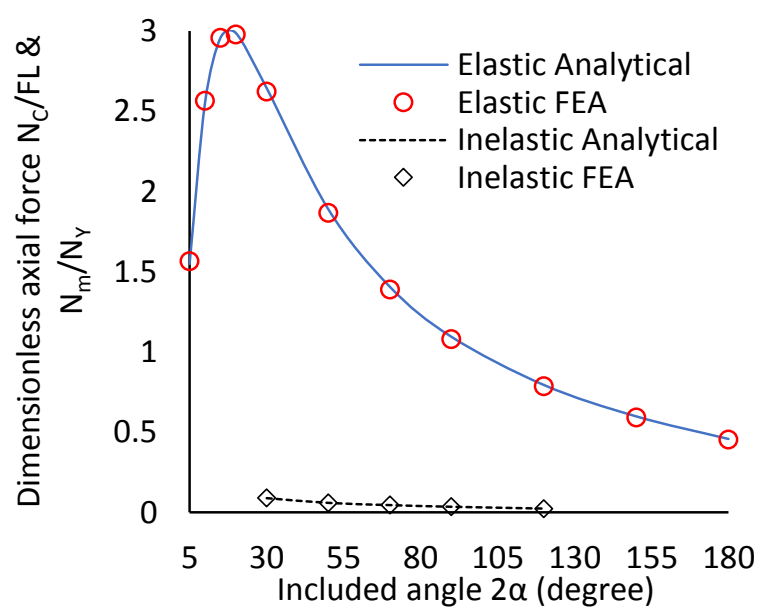

(A)
The negative sign from Table 4 represents the downward applied transverse point load. Similar to the investigated channel arches, the same 11 included angles were used to validate the elastic FE model. However, due to computational time involved with the non-linear analysis, only the 30, 50, 70, 90 and 120 included angles were used to validate the inelastic FE models. The obtained prebuckling results were presented graphically, with the prebuckling parameters in their dimensionless form as the abscissa and the included angles, $2 \alpha$ as the ordinates. The dimensionless forms were as follow;

- Dimensionless elastic axial compression force, $N_{C} / F$ ( $F$ is the unit applied load in N)

- Dimensionless elastic bending moment, $4 M_{C} / F L$

- Dimensionless inelastic axial compression force, $N_{m} / N_{Y}$ $\left(N_{Y}\right.$ is the squash load in $\left.\mathrm{N}\right)$

- Dimensionless inelastic bending moment, $M_{m} / M_{P}\left(M_{P}\right.$ is the plastic moment of the cross-section in $\mathrm{Nm}$ )

\section{RESULTS AND DISCUSSION}

In this section, the results obtained from the methods described in the preceding sections are presented graphically and discussed. The first results present a validation of the FE model against existing theoretical solutions. Further, the prebuckling results of the investigated channel arches are presented, and their effects on the LTB loads and behaviour are discussed in the sections that compare the elastic and inelastic LTB loads.

\subsection{Preliminary validation of results}

In this section, both the elastic and inelastic prebuckling analytical solutions were used to validate the elastic and inelastic FE models, respectively; that is, the LEA and MNA. The dimensionless prebuckling results at the crown that is ; $N_{C} / F L, \quad N_{m} / N_{Y}$ and bending moments, that is; $4 M_{C} / F L, M_{m} / M_{P}$ are plotted on separate graphs. Figure 9 presents the comparison between the elastic and inelastic analytical and FEA prebuckling results.

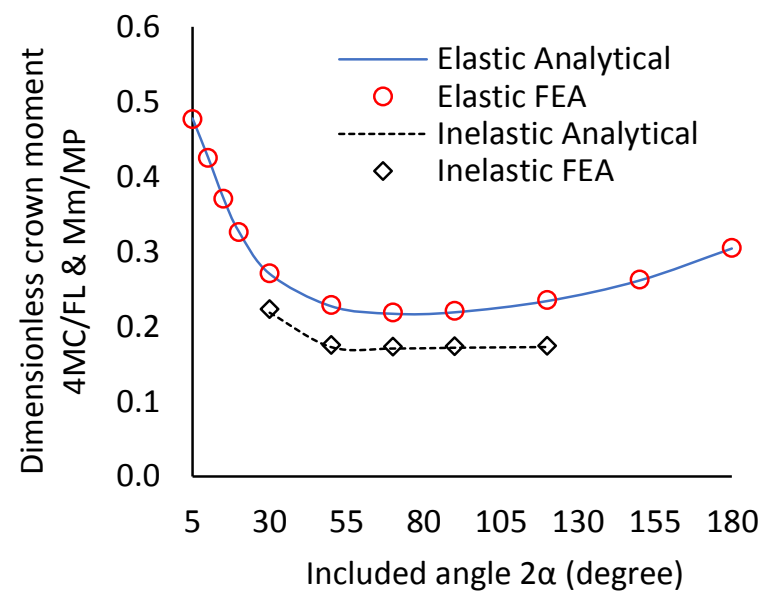

(B)

Figure 9: Elastic and inelastic comparison of the finite element and theoretical results (A) axial compressive force and

(B) bending moment at the crown at various included angles 
From Figure 9, it was observed that the results obtained from the different methods that are; FEA and analytical yielded results with insignificant variances for both axial compressive force and bending moment. Therefore, it was concluded that the methods used to develop the FE models were accurate, efficient and could represent the expected behaviour of channel sections arches. Thus, the procedure used to develop the aluminium channel FE models, which were discussed in the sections that follow was deemed correct.

\subsection{Presentation and discussion of prebuckling results}

The elastic and inelastic axial compressive forces and bending moments at the crown for the channel profiles are compared in this section. The comparisons are structured such that elastic and inelastic axial compressive forces were reported separately from the elastic and inelastic bending moments. In each section, the arches were further grouped into those developed at the constant span length $(L=500 \mathrm{~mm})$ and those developed at the constant slender ratios $\left(S / r_{x}=60\right.$ and 90$)$. The primary purpose of these comparisons was to evaluate the differences in behaviour and magnitudes of prebuckling caused by the applied imperfections.

\subsubsection{Comparison of the elastic and inelastic axial compressive forces}

The comparison of the elastic and inelastic axial compressive forces behaviours was examined for arches developed at the constant span length and those developed at constant slender ratios separately in the following sub-sections.

\subsubsection{Elastic and inelastic axial compressive forces of arches developed at constant span length}

The variation of $N_{C} / F L$ and $N_{m} / N_{Y}$ at respective included angles, $2 \alpha$ for arches developed at constant span length $L=500 \mathrm{~mm}$ are presented in Figure $\mathbf{1 0}$.

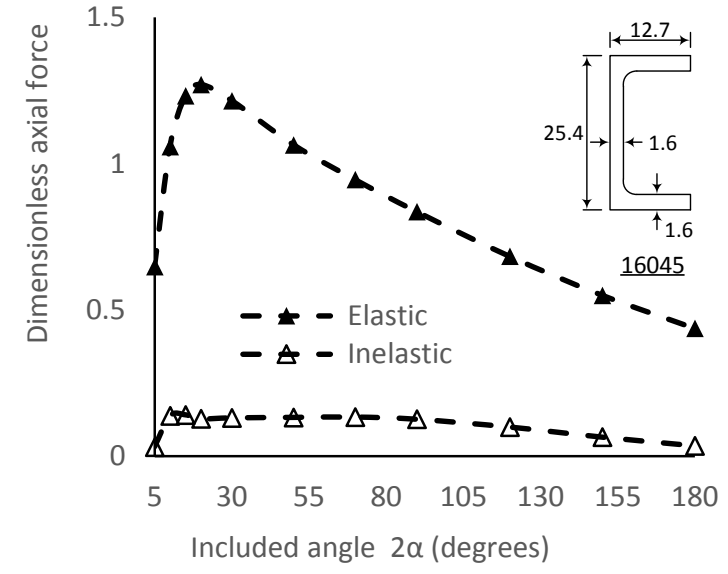

(a) Profile 16045 at $L=500 \mathrm{~mm}$

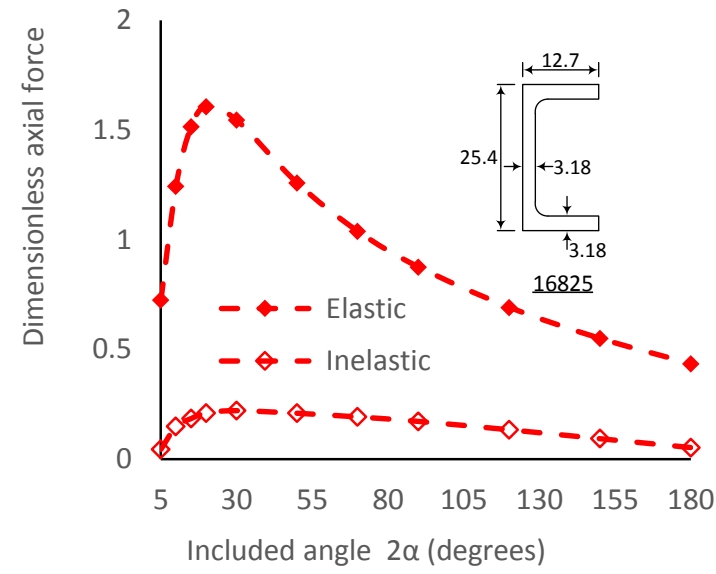

(b) Profile 16825 at $L=500 \mathrm{~mm}$

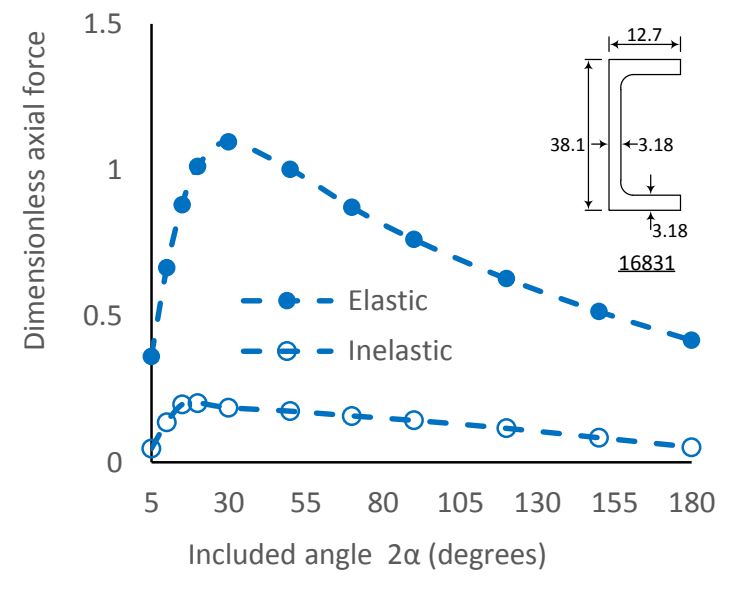

(c) Profile 16831 at $L=500 \mathrm{~mm}$

Figure 10: Comparison of elastic and inelastic dimensionless axial compressive force for arches developed at constant span length 
From Figure 10, it was noted that all the arches axial compressive forces first increased to peaks and then decreased with a continued increase of the included angles. However, the increases and decreases for elastic analyses were more significant, compared to those of inelastic analyses. These differences in magnitudes were due to the imperfections. This implied, the imperfections only influenced the magnitudes of the axial compressive forces and not their behaviours. Based on the axial compressive force's influence on the LTB loads as reported by Pi and Bradford (2003) study, one would expect the inelastic LTB loads to be lower than the elastic LTB load due to their overall low axial compressive forces.

\subsubsection{Elastic and inelastic axial compressive forces of arches developed at constant slender ratios}

Typical variation of $N_{C} / F L$ and $N_{m} / N_{Y}$ at respective included angles for arches developed at the constant slender ratios of 60 and 90, respectively, are shown in Figure $\mathbf{1 1}$.

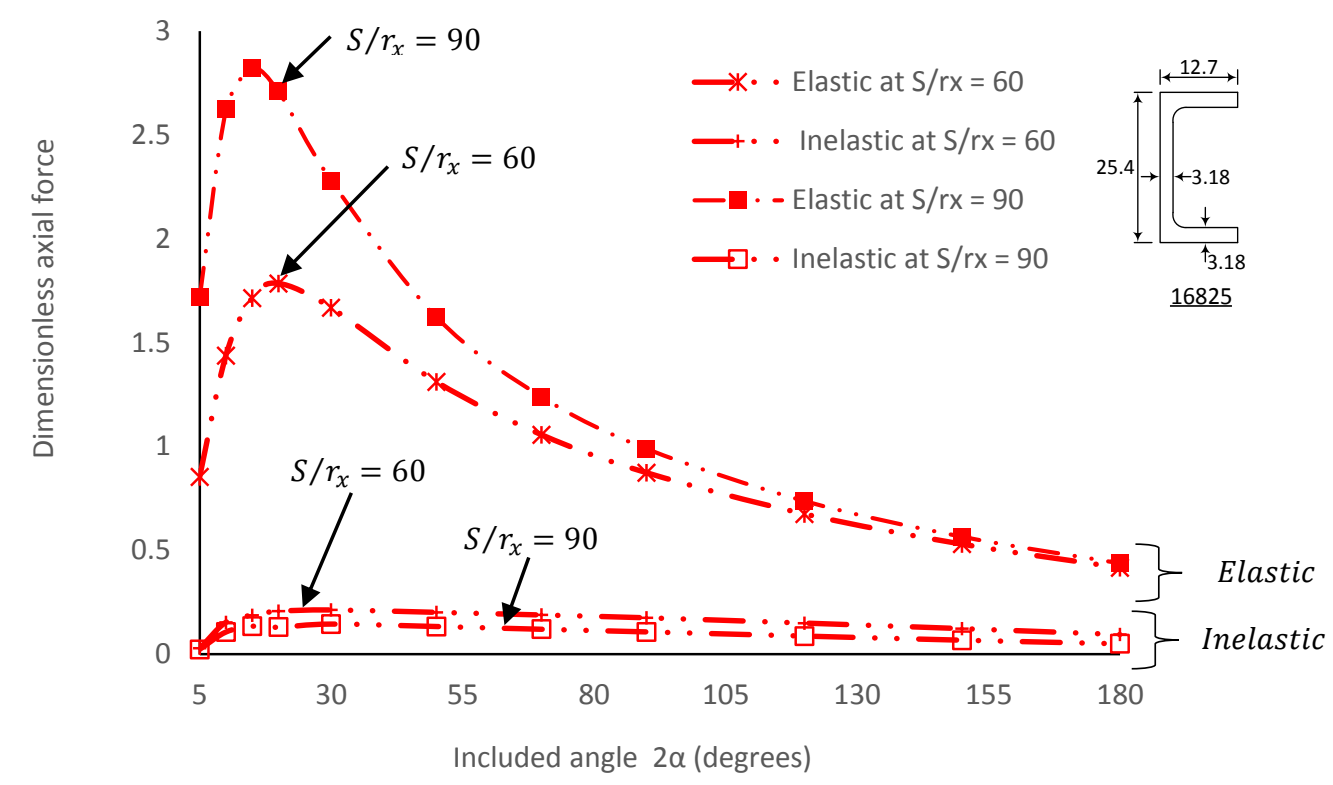

Figure 11. Comparison of elastic and inelastic dimensionless axial compressive force for arches developed at constant slender ratios

As illustrated in Figure 11, all the arches axial compressive forces first increased to peak values and then decreased with continued increase of the included angles. Both inelastic axial compressive forces showed slight changes in magnitudes, compared to those of elastic axial compressive forces. Also, it was noticed that the overall elastic axial compressive forces for arches developed at $S / r_{x}=90$ were higher, while their inelastic axial compressive forces were lower. The exceedingly high magnitudes of the elastic axial compressive forces showed the influence of the applied imperfections in prebuckling that resulted in the overall low inelastic axial compressive forces for both slender ratios. Again, the imperfections influenced the magnitudes significantly, as compared to the behaviours.

\subsubsection{Elastic and inelastic bending moments of arches developed at constant span length}

The variation of the $4 M_{C} / F L$ and $M_{m} / M_{P}$, for arches developed at constant span length $L=500 \mathrm{~mm}$ at respective included angles, $2 \alpha$ are presented in Figure 12. 


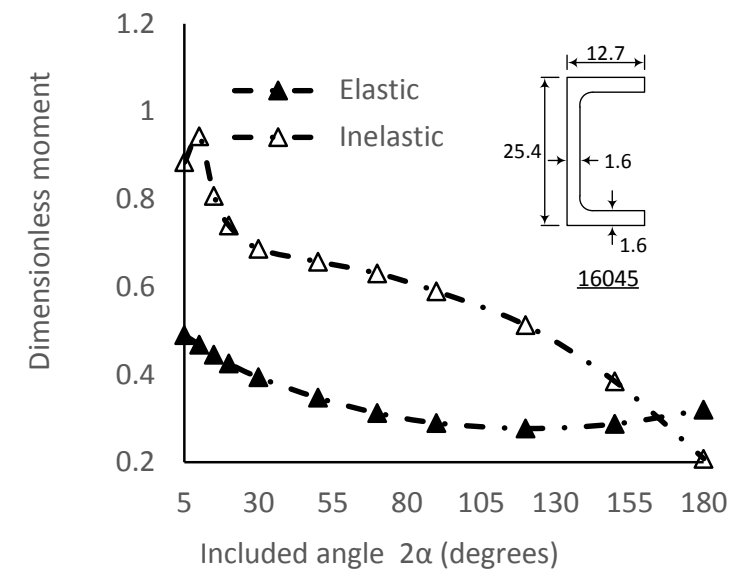

(a) Profile 16045 at $L=500 \mathrm{~mm}$

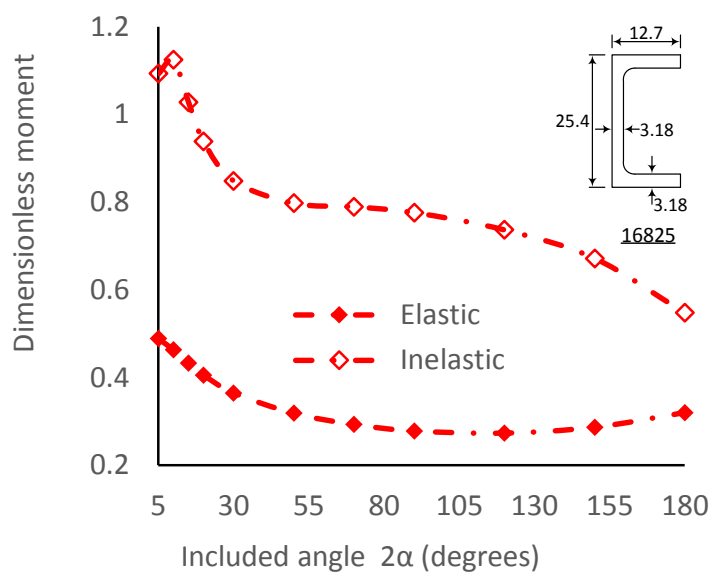

(b) Profile 16825 at $L=500 \mathrm{~mm}$

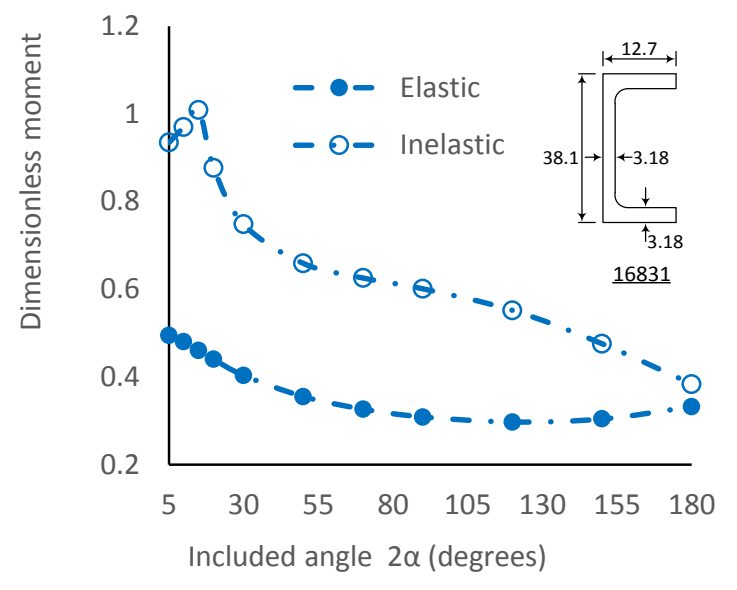

(c) Profile 16831 at $L=500 \mathrm{~mm}$

Figure 12: Comparison of the elastic and inelastic dimensionless central bending moment for arches developed at constant span length

It can be seen in Figure 12 that the elastic and inelastic general behaviour differs for most of the plots, as the elastic bending moments increased, the inelastic bending moment's decreases and vice versa. More significant differences were observed for very shallow arches, where the inelastic bending moment gradually increased while the elastic bending moment continued to decrease. Also, it was noticed that the overall elastic bending moments were lower, compared to their inelastic counterparts. The high magnitudes noticed for the inelastic bending moments indicated that the influence of imperfections due to the increase in the bending stresses along the flange edge caused by the applied imperfections. However, as the included angles increases, the increased of the bending stress by applied imperfections (in this case, the residual stresses) started to reduce. As the bending stress decreases with increase in the included angle, a redistribution of the bending moment occurs and contributes insignificantly to the arch stiffness as seen at $2 \alpha>150^{\circ}$ as shown in Figure 12 (a). In summary, the imperfections were observed to have significantly influenced the magnitudes and behaviour of the bending moments.

\subsubsection{Elastic and inelastic bending moments of arches developed at the constant slender ratios}

Typical variation of $4 M_{C} / F L$ and $M_{m} / M_{P}$ for arches developed at $S / r_{x}=60$ and 90 at respective included angles, $2 \alpha$ are presented in Figure 13. 


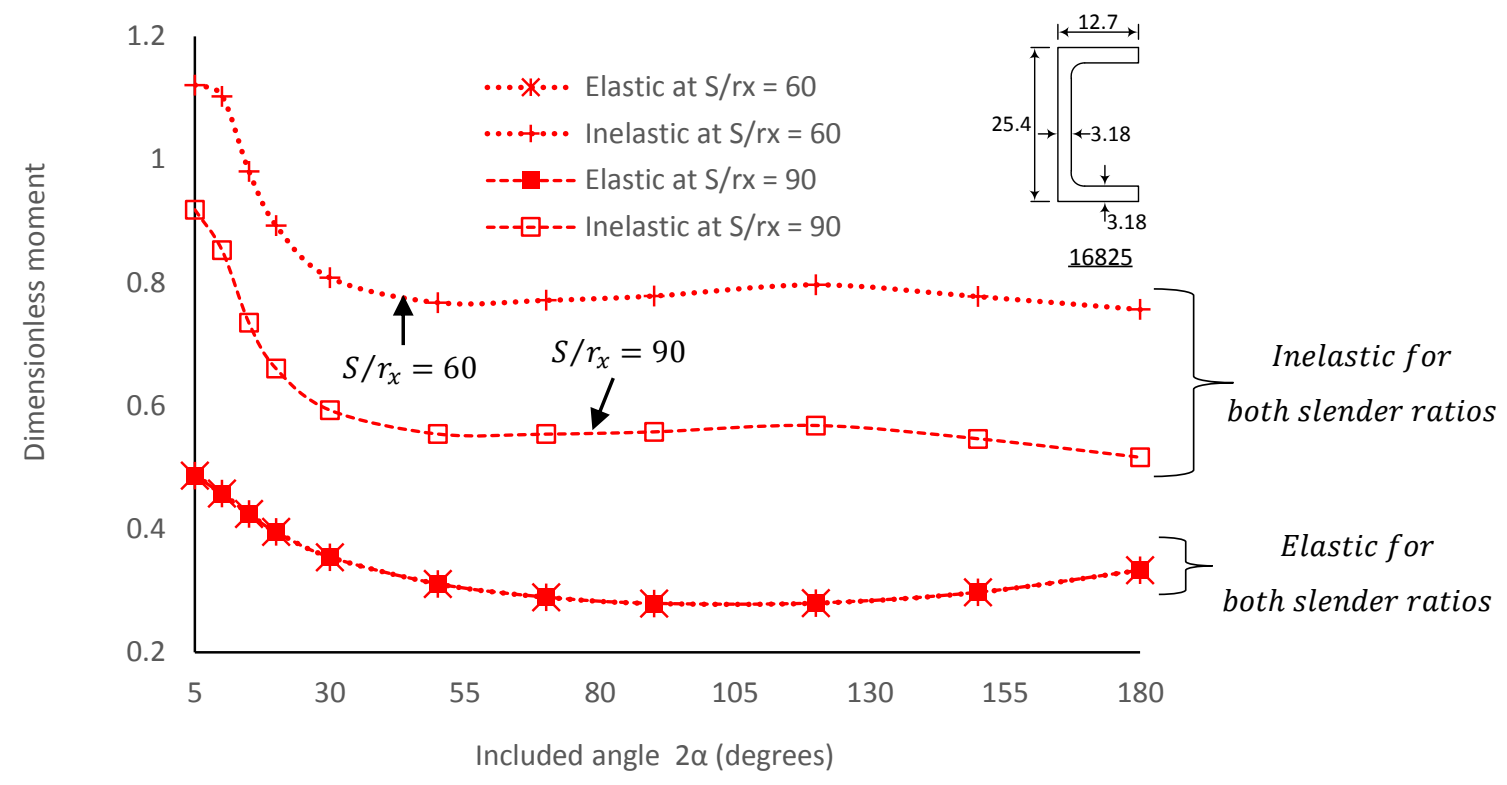

Figure 13: Comparison of the elastic and inelastic dimensionless central bending moment for arches developed at constant slender ratios

It was observed from Figure $\mathbf{1 3}$ that for most of the included angles, both the elastic and inelastic dimensionless bending moments behaved alike with a very slight variance between the elastic bending moments. The observed high inelastic bending moments for both slender ratios, compared to their elastic counterparts were due to the influence of the imperfections, because of the high bending stresses induced in the arch members. In addition, from the difference in magnitudes, the inelastic LTB loads for arches developed at $S / r_{x}=60$ should be greater than those developed at $S / r_{x}=90$ as observed in Pi and Bradford (2003) study. In summary, the change in slender ratios appeared to have a significant impact on the bending moments' magnitude and slight influence on general behaviour.

\subsection{Comparison of elastic and inelastic lateral-torsional buckling loads}

The elastic critical buckling loads $\left(F_{c r}\right)$ and inelastic buckling loads $\left(F_{u l t}\right)$ are compared in this section. These comparisons are to assimilate better the impact of the imperfections on the LTB loads. For arches developed at constant span length, the elastic and inelastic LTB loads were compared for the distinctive channel sections with part numbers 16045, 16825 and 16831. For arches developed at constant slender ratios, comparisons were also made between the elastic and inelastic LTB loads, that is; buckling loads at $S / r_{x}=60$ were compared separately from those obtained at $S / r_{x}=90$. It is important to note that the points of interest for the comparisons were the maximum and minimum LTB loads as typical in designs of the strength of a material. The curves used for measurements as references were those with an overall high LTB load-carrying capacity. The comparisons of the elastic and inelastic LTB loads of the arches developed at constant span length $L=500$ $\mathrm{mm}$ are first presented, followed by those developed at $S / r_{x}=$ 60 and 90 , respectively.

3.3.1 Comparison of the elastic and inelastic lateraltorsional buckling loads of arches developed at constant span length

The elastic and inelastic LTB loads compared in this section are for arches developed at the constant span length $L=500 \mathrm{~mm}$. These include all three channels numbered 16045, 16825 and 16831. These comparisons are to provide detailed information on the effects of imperfections on the LTB loads of such arches.

\subsubsection{Assessments on the effects of imperfections on the lateral-torsional buckling loads of arches developed from profile 16045 at constant span length}

A typical comparison between $F_{c r}$ and $F_{u l t}$ at included angles, $2 \alpha$ for arches developed $L=500 \mathrm{~mm}$ from profile 16045 are presented in Figure 14. 


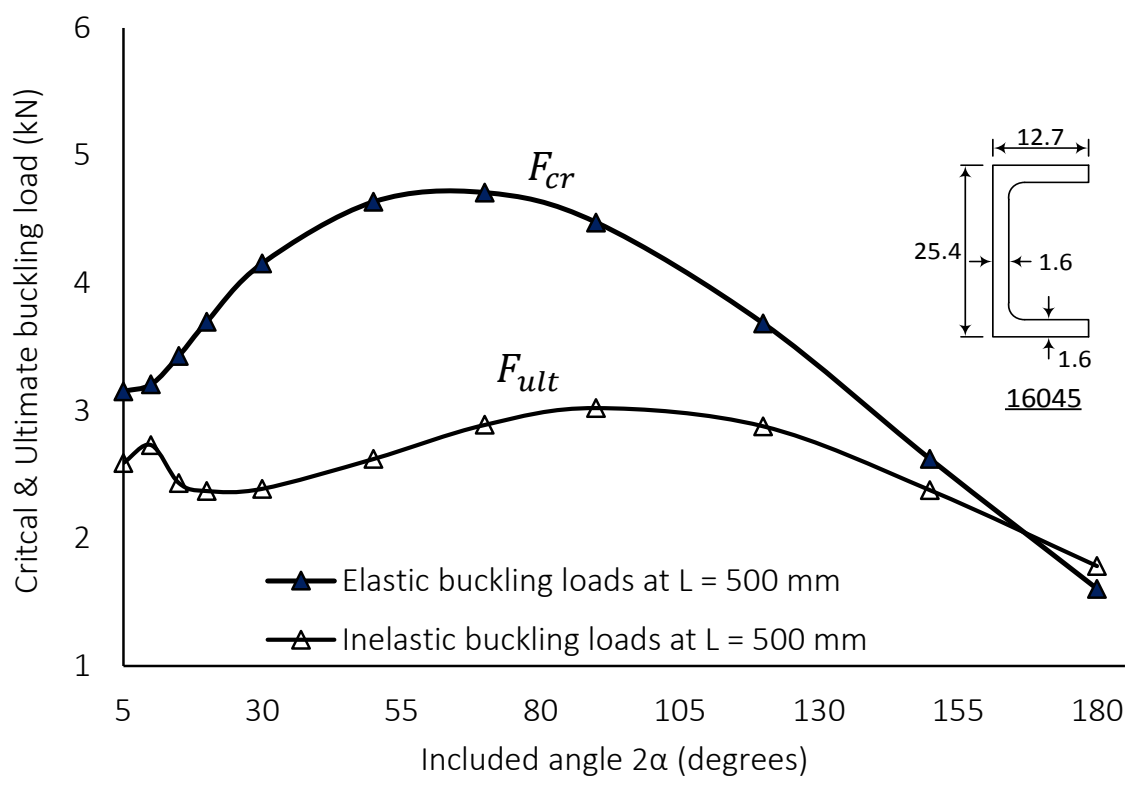

Figure 14: Comparison of the critical and ultimate lateral-torsional buckling loads for profile 16045

It can be seen in Figure 14 that at included angles $2 \alpha>30$, both the elastic and inelastic buckling loads increased to their maximums before they decreased. While at $5^{\circ}<2 \alpha<30^{\circ}$ included angle, as the elastic buckling load increased continuously, its inelastic counterpart increased and decreased. The observed behaviours of the elastic and inelastic LTB loads were associated with the axial compressive forces and bending moments shown in Figure 10 (a) and Figure 12 (a). The overall magnitudes of the elastic LTB loads can be attributed to the overall high magnitude of the elastic axial compressive forces in Figure 10 (a) and the low elastic bending moments in Figure 12 (a) and vice versa. Besides, the point at which the $F_{c r} \leq F_{u l t}$ was also associated with bending moments in Figure 12 (a). Further, the overall high elastic LTB loads indicated the overestimation of the expected real LTB loads. The maximum and minimum LTB loads and their respective percentage differences are summarised in Table 5. The curve of the elastic LTB loads was used as a reference for measurements due to its overall high elastic LTB loads.

Table 5: The maximum and minimum elastic and inelastic LTB loads differences in percentages for arches developed at constant span length from profile 16045

\begin{tabular}{|c|c|c|c|c|c|}
\hline $\begin{array}{l}\text { The percentage difference between the } \\
\text { maximum elastic LTB load and the } \\
\text { corresponding inelastic LTB load }\end{array}$ & \multicolumn{2}{|c|}{$\begin{array}{l}\text { The percentage difference between the } \\
\text { minimum elastic LTB load and the } \\
\text { corresponding inelastic LTB load }\end{array}$} & $\begin{array}{l}\text { The maximum difference in } \\
\text { percentage }\end{array}$ \\
\hline Included angle $2 \alpha$ in $\left(^{\circ}\right)$ & $\begin{array}{c}\text { (percent) } \\
\%\end{array}$ & $\begin{array}{c}\text { Included angle } 2 \alpha \\
\text { in }\left(^{\circ}\right)\end{array}$ & (percent) $\%$ & $\begin{array}{c}\text { Included angle } 2 \alpha \\
\text { in }\left({ }^{\circ}\right)\end{array}$ & $\begin{array}{c}\text { (percent) } \\
\%\end{array}$ \\
\hline 70 & 47.9 & 180 & -10.5 & 50 & 55.5 \\
\hline
\end{tabular}

From Table 5, it can be seen that by application of the imperfections, the maximum elastic LTB load overestimated the expected real LTB load by up to 47.9 percent at the relative included angle. However, it so happened that the highest by which the elastic LTB loads overestimated the real LTB load was up to 55.5 percent at $50^{\circ}$ included angle. The negative percentage $(-10.5$ percent $)$ indicated that at the $180^{\circ}$ included angle where the lowest LTB loads occurred, the elastic buckling load underestimated the inelastic by 10.5 percent; that is, the negative sign represents an increase of the $F_{\text {ult }}$ above the $F_{c r}$. In general, the elastic LTB were found to have overestimated the inelastic LTB buckling loads for all shallow and moderate arches, indicating the influence of imperfections on the LTB loads are less significant for deep arches. 


\subsubsection{Assessments on the effects of imperfections on the lateral-torsional buckling loads of arches developed from profile 16825 at constant span length}

Similar to profile 16045, a typical comparison between $F_{c r}$ and $F_{u l t}$ at the included angles $2 \alpha$ for arches developed from profile 16825 at the constant span length, $L=500 \mathrm{~mm}$ are presented in Figure 15.

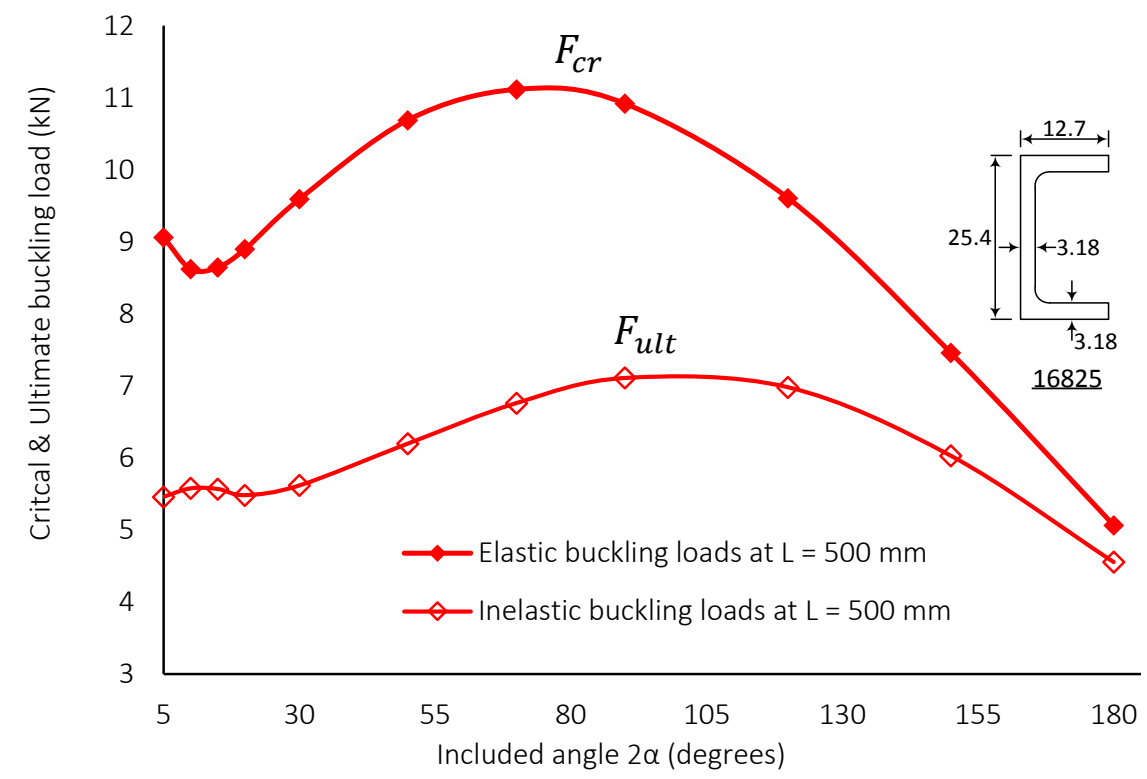

Figure 15: Comparison of the critical and ultimate lateral-torsional buckling loads for profile 16825

It can be seen in Figure 15 that for included angles $2 \alpha<20^{\circ}$, the behaviours of the elastic and inelastic LTB loads are opposing each other similar to those reported for profile 16045. However, for included angles $2 \alpha>20^{\circ}$, both elastic and inelastic LTB loads increased to their peak values before they decreased to their respective minimum values with the elastic LTB loads showing a more significant rate of decrease. These differences in behaviours were attributed to the combined axial compressive and bending actions on the LTB load in Figure $\mathbf{1 0}$ (b) and Figure 12 (b). Furthermore, the overall high elastic LTB loads revealed the overestimation of the expected real LTB loads. Therefore, the percentage difference between the maximum and minimum elastic and inelastic LTB loads are presented in Table 6. Again, the elastic LTB loads plots, as shown in Figure 15, was used as the reference for measurements.

Table 6: The maximum and minimum elastic and inelastic LTB loads differences in percentages for arches developed at constant span length from profile 16825

\begin{tabular}{|c|c|c|c|c|c|}
\hline $\begin{array}{c}\text { The percentage difference between the } \\
\text { maximum elastic LTB load and the } \\
\text { corresponding inelastic LTB load }\end{array}$ & $\begin{array}{c}\text { The percentage difference between the } \\
\text { minimum elastic LTB load and the } \\
\text { corresponding inelastic LTB load }\end{array}$ & \multicolumn{3}{|c|}{$\begin{array}{c}\text { The maximum difference } \\
\text { in percentage }\end{array}$} \\
\hline $\begin{array}{c}\text { Included angle } 2 \alpha \\
\text { in }\left(^{\circ}\right)\end{array}$ & $\begin{array}{c}\text { (percent) } \\
\%\end{array}$ & $\begin{array}{c}\text { Included angle } 2 \alpha \text { in } \\
\left({ }^{\circ}\right)\end{array}$ & $\begin{array}{c}\text { (percent) } \\
\%\end{array}$ & $\begin{array}{c}\text { Included angle } 2 \alpha \text { in } \\
\left({ }^{\circ}\right)\end{array}$ & $\begin{array}{c}\text { (percent) } \\
\%\end{array}$ \\
\hline 70 & 48.7 & 180 & 10.6 & 50 & 53.1 \\
\hline
\end{tabular}

From Table 6, it was noted that by interduction of the imperfections, the maximum elastic LTB load overestimated the expected real buckling load by up to 48.7 percent at the corresponding included angle. Further, it happened that the maximum percentage by which the elastic LTB load overestimated the real buckling was up to 53.1 percent at $50^{\circ}$ 
included angle. Furthermore, at the lowest LTB loads at $180^{\circ}$ included angles, the elastic LTB load only overestimated the real LTB load by only 10.6 percent. These results indicated that the effects of imperfections on the LTB loads are more significant at included angles were high resistance to LTB are expected. Generally, on average the elastic LTB loads overestimated the inelastic LTB loads by up 40 percent. These differences indicated the effects of the applied imperfections on the LTB load-carrying capacity.

\subsubsection{Assessments on the effects of imperfections on the lateral-torsional buckling loads of arches developed from profile 16831 at constant span length}

A typical comparison between $F_{c r}$ and $F_{u l t}$ at included angles $2 \alpha$ for arches developed from profile 16831 at the constant span length $L=500 \mathrm{~mm}$ are presented in Figure 16.

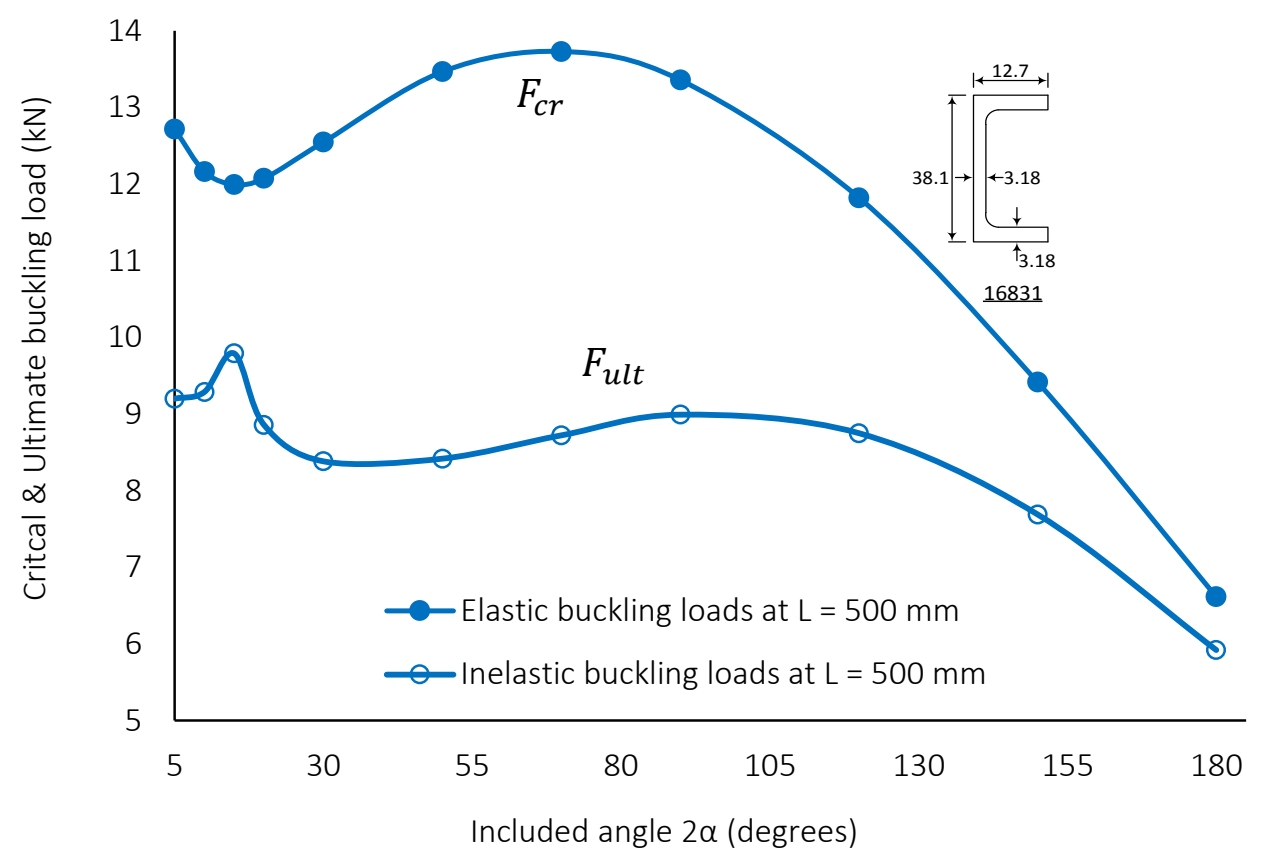

Figure 16: Comparison of the critical and ultimate lateral-torsional buckling loads for profile 16831

It can be seen in Figure 16 that at included angle $2 \alpha<30^{\circ}$, the elastic and inelastic LTB loads behaved in an opposite manner, such as those reported for profiles 16825 and 16045; as the elastic LTB loads decreased, the inelastic LTB loads increased and vice versa. Furthermore, at $2 \alpha>30^{\circ}$, both LTB loads increased to some maximum values before decreasing to their minimum values with significant decreasing rate noticed for the elastic LTB loads. These behaviours resulted from the combined axial compressive and bending actions on the LTB loads, as shown in Figure $10(\mathbf{c})$ and Figure $12(\mathbf{c})$. For the high elastic LTB loads, it is evident that the applied imperfections had significant effects on the LTB loads at all included angles. Table 7 summarises the percentage difference between the maximum and minimum elastic and inelastic LTB loads, respectively. Due to the overall high elastic LTB load, its curve as shown in Figure $\mathbf{1 6}$ was used as the reference for measurement.

Table 7: The maximum and minimum elastic and inelastic LTB loads differences in percentages for arches developed at constant span length from profile 16831

\begin{tabular}{|c|c|c|c|c|c|}
\hline $\begin{array}{l}\text { The percentage difference between the } \\
\text { maximum elastic LTB load and the } \\
\text { corresponding inelastic LTB load }\end{array}$ & $\begin{array}{l}\text { The percentage difference between the } \\
\text { minimum elastic LTB load and the } \\
\text { corresponding inelastic LTB load }\end{array}$ & $\begin{array}{l}\text { The maximum difference in } \\
\text { percentage }\end{array}$ \\
\hline Included angle $2 \alpha$ in $\left(^{\circ}\right)$ & $\begin{array}{c}\text { (percent) } \\
\%\end{array}$ & $\begin{array}{c}\text { Included angle } 2 \alpha \\
\text { in }\left(^{\circ}\right)\end{array}$ & $\begin{array}{c}\text { (percent) } \\
\%\end{array}$ & $\begin{array}{c}\text { Included angle } \\
2 \alpha \text { in }\left(^{\circ}\right)\end{array}$ & $\begin{array}{c}\text { (percent) } \\
\%\end{array}$ \\
\hline 70 & 44.6 & 180 & 11.1 & 70 & 44.6 \\
\hline
\end{tabular}


From Table 7, it was observed that having applied the imperfections, the maximum elastic LTB load overestimated real LTB load by up to 44.6 percent at the relative included angle. The 44.6 percent at $70^{\circ}$ included angle happens to be the maximum percentage difference across the included angles. This occurrence indicated that the maximum impact of the applied imperfections occurred at $70^{\circ}$ included angle. Also, at the lowest LTB loads, the least percentage difference of 11.1 percent was observed between the elastic and inelastic LTB loads. Again, this occurrence indicated that the lowest impact of the applied imperfections on the LTB loads occurred at $180^{\circ}$ included angle. On average, the elastic LTB loads were noticed to have overestimated the supposed real LTB load by up to 40 percent.
3.3.2 Comparison of the elastic and inelastic lateraltorsional buckling loads of arches developed at the constant slender ratios of 60 and 90

The elastic and inelastic LTB loads for arches developed at $S / r_{x}=60$ and 90 from profile 16825 are compared in this section.

3.3.2.1 Assessments on the effects of imperfections on the lateral-torsional buckling loads of arches developed from profile 16825 at constant slender ratio 60

A typical comparison between $F_{c r}$ and $F_{u l t}$ at included angles $2 \alpha$ of arches developed at $S / r_{x}=60$ from profile 16825 , is presented in Figure 17.

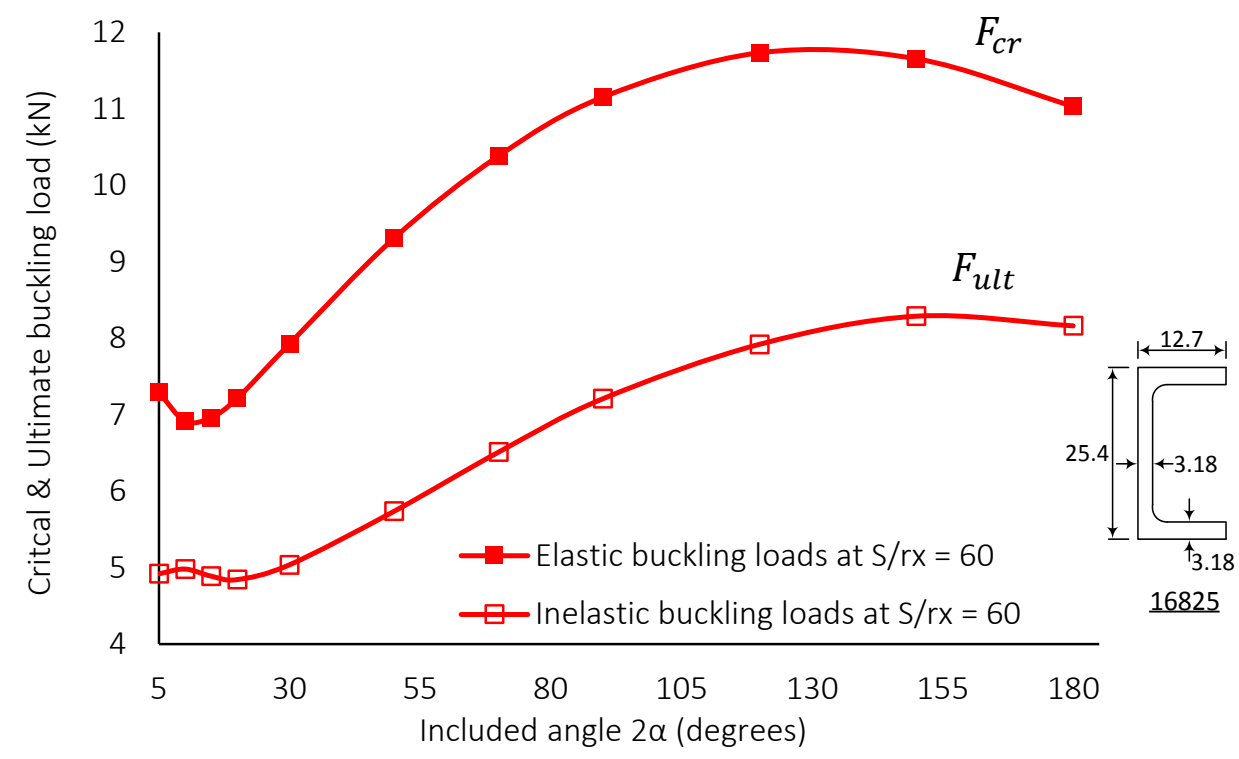

Figure 17: Comparison of the critical and ultimate lateral-torsional buckling loads for profile 16825 developed at slender ratio 60

It can be seen in Figure 17 that at included angles $2 \alpha \leq 20^{\circ}$, as the elastic LTB loads decreased, its inelastic counterpart increased and vice versa. However, at $2 \alpha>20^{\circ}$ both the elastic and inelastic LTB loads increased to their peaks and decreased slightly after that. These differences in behaviour were associated with the combined axial compressive and bending actions on the LTB loads shown in Figure $\mathbf{1 1}$ and Figure 13. The overall low magnitude noticed for the inelastic LTB loads were reflections of the effects by the applied imperfections on the LTB loads. These imperfections, such as the geometric imperfection and residual stresses, cause initial low and high bending stress, respectively.

Further, the results revealed that the elastic LTB loads overestimated the expected real LTB loads. The percentage difference between the maximum and minimum elastic and inelastic LTB loads, respectively, are summarised in Table 8. It is important to note that the curve of the elastic LTB loads shown in Figure 17 was used as the reference for measurements due to its overall high LTB loads.

Table 8: The maximum and minimum elastic and inelastic LTB loads differences in percentages for arches developed at constant slender ratio 60 from profile 16825

\begin{tabular}{|c|c|c|c|c|c|}
\hline \multicolumn{2}{|c|}{$\begin{array}{l}\text { The percentage difference between the } \\
\text { maximum elastic LTB load and the } \\
\text { corresponding inelastic LTB load }\end{array}$} & \multicolumn{2}{|c|}{$\begin{array}{l}\text { The percentage difference between the } \\
\text { minimum elastic LTB load and the } \\
\text { corresponding inelastic LTB load }\end{array}$} & \multicolumn{2}{|c|}{$\begin{array}{l}\text { The maximum difference in } \\
\text { percentage }\end{array}$} \\
\hline Included angle $2 \alpha$ in $\left(^{\circ}\right)$ & $\begin{array}{c}\text { (percent) } \\
\%\end{array}$ & $\begin{array}{c}\text { Included angle } 2 \alpha \\
\text { in }\left({ }^{\circ}\right)\end{array}$ & $\begin{array}{c}\text { (percent) } \\
\%\end{array}$ & $\begin{array}{c}\text { Included angle } \\
2 \alpha \text { in }\left(^{\circ}\right)\end{array}$ & $\begin{array}{c}\text { (percent) } \\
\%\end{array}$ \\
\hline 120 & 38.8 & 180 & 29.9 & 50 & 47.5 \\
\hline
\end{tabular}


As observed in Table 8, by application of the imperfections, the maximum elastic LTB load overestimated real LTB load by up to 38.8 percent for the included angle of $120^{\circ}$. Meanwhile, the lowest elastic LTB load again overestimated the corresponding inelastic LTB load by up to 29.9 percent at $2 \alpha=180^{\circ}$. The aforementioned percentage differences represented the impacts of the applied imperfections on the LTB loads. Also, it was noticed that the imperfections appeared to have their maximum impact at $2 \alpha=50^{\circ}$, where the elastic LTB load overestimated the expected real LTB load by up to 47.5 percent. Overall, the elastic LTB loads overestimated the expected real LTB loads by close to 40 percent on average, indicating the influence of the applied imperfections on the LTB loads.

\subsubsection{Assessments on the effects of imperfections on the lateral-torsional buckling loads of arches developed from profile 16825 at constant slender ratio 90}

A typical comparison between $F_{c r}$ and $F_{u l t}$ at included angles $2 \alpha$ for arches developed at $S / r_{x}=90$ from profile 16825 is presented in Figure 18.

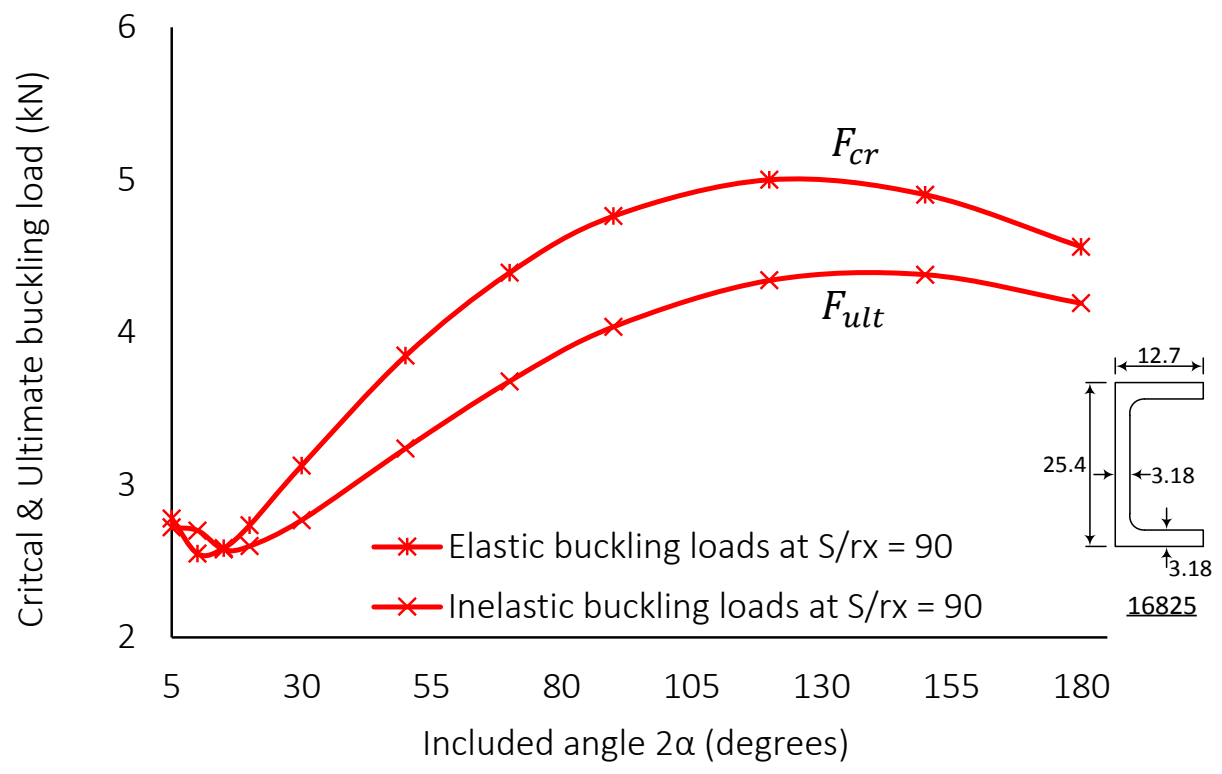

Figure 18: Comparison of the critical and ultimate lateral-torsional buckling loads for profile 16825 developed at slender ratio 90

It can be seen in Figure $\mathbf{1 8}$ that both the elastic and inelastic LTB loads first decreased to their minimum values and then increased to their maximum values before slightly decreasing again with the continued increase of included angles. At $2 \alpha<$ $20^{\circ}$, an insignificant difference was observed between the elastic and inelastic LTB loads. At that range, the inelastic LTB loads were noticed to be higher than their elastic counterparts. Nevertheless, at $2 \alpha>20^{\circ}$, the elastic LTB loads were higher than their inelastic counterparts, and significant differences were also noticed between the loads. These behaviours were associated with the combined axial compressive and bending actions on the LTB loads, as shown in Figure 11 and Figure 13.

Regarding the LTB loads magnitudes, the overall low inelastic LTB loads at $2 \alpha>20^{\circ}$ showed the impact of the applied imperfections on the LTB loads to be more significant. Hence, an ideal analysis would overestimate the expected real LTB loads at those included angles and vice versa. The percentage difference between the maximum and minimum elastic and inelastic LTB loads, respectively, are summarised in Table 9. Again, the elastic LTB loads curve was used as the reference for measurement due to its overall high magnitude.

Table 9: The maximum and minimum elastic and inelastic LTB load differences in percentages for arches developed at constant slender ratio 90 from profile 16825

\begin{tabular}{|c|c|c|c|c|c|}
\hline $\begin{array}{l}\text { The percentage difference between the } \\
\text { maximum elastic LTB load and the } \\
\text { corresponding inelastic LTB load }\end{array}$ & $\begin{array}{l}\text { The percentage difference between the } \\
\text { minimum elastic LTB load and the } \\
\text { corresponding inelastic LTB load }\end{array}$ & $\begin{array}{l}\text { The maximum difference in } \\
\text { percentage }\end{array}$ \\
\hline Included angle, $2 \alpha$ in $\left(^{\circ}\right)$ & $\begin{array}{c}\text { (percent) } \\
\%\end{array}$ & $\begin{array}{c}\text { Included angle } 2 \alpha \\
\text { in }\left(^{\circ}\right)\end{array}$ & $\begin{array}{c}\text { (percent) } \\
\%\end{array}$ & $\begin{array}{c}\text { Included angle } \\
2 \alpha \text { in }\left(^{\circ}\right)\end{array}$ & $\begin{array}{c}\text { (percent) } \\
\%\end{array}$ \\
\hline 120 & 14.1 & 10 & -5.8 & 70 & 17.6 \\
\hline
\end{tabular}


From Table 9, it is noted that by application of the imperfections, the maximum elastic LTB load overestimated the corresponding inelastic LTB load by just 14.1 percent. Meanwhile, the maximum impact of the imperfections on the LTB loads across the included angles was noticed to be up to 17.6 percent at included angle $2 \alpha=70^{\circ}$. In addition, the elastic LTB load was realised to have underestimated the expected real LTB load by 5.8 percent only. The underestimation of the inelastic LTB load explained the negative difference in percentage shown in Table 9. On average, the elastic LTB loads were found to have overestimated the inelastic LTB loads by just 9 percent. This percentage indicated that the effects of the imperfections on the LTB loads become less significant as the increase of the slender ratio continues.

\section{CONCLUSION}

1. Comparison of the results obtained from FEA with current analytical methods revealed strong agreement, indicating that the FE models were reliable, efficient and accurate in terms of the model nodes and elements used.

2. For arches developed at constant span length and at constant slender ratios, the elastic axial compressive forces have significant high magnitudes as compared to the inelastic analyses and vice versa for the bending moments, indicating the influence of the imperfections.

3. For arches developed at constant span length, for an arch with a high elastic axial compressive force as compared to its inelastic counterpart, one should expect the elastic LTB load to overestimate the real buckling load and vice versa. Meanwhile, for a high inelastic bending moment as compared to its elastic counterpart, one should expect the elastic LTB load to overestimate the real buckling load and vice versa.

4. All the investigated channel arches showed the imperfections to have significant impacts on the LTB loads, and imperfections impact on the LTB loads were different for all the arches.

5. For channel section arches with web to flange width ratio of 2, that is; profile 16825 and 16045 developed at the constant span length, the maximum elastic LTB load overestimated the expected real LTB load by 48.7 percent and 47.9 percent, respectively. Also, for profile 16831 with a web to flange width ratio of 3 , the maximum elastic LTB load overestimated the real LTB load by approximately 44.6 percent. In summary, as the web to flange width ratio increases the percentage by which the elastic LTB load overestimated the real bucking load decreases and vice versa. Also, at such web to flange width ratio, the elastic analysis would not be suitable for designs of such arches.

6. The maximum elastic LTB load at $S / r_{x}=60$ overestimated its inelastic counterpart by 38.8 percent, while the maximum elastic LTB load at $S / r_{x}=90$ overestimated its inelastic counterpart by only 14.1 percent. This occurrence revealed that as the slender ratios decrease for such arches, the effect of imperfections decreases and vice versa.

7. In summary, it is evident from the investigated arches that, for design purpose, the elastic analysis is not suitable as it overestimates the expected real buckling load that can cause catastrophic failure if not accounted for in the designs.

\section{RECOMMENDATIONS}

1. Since the techniques used to construct the finite element model have been tested and have demonstrated strong compatibility with current approaches, experimental analysis on the real models examined should be performed to better support the findings provided in this report.

2. From the reviewed literature, the load position may also impact the real buckling load significantly. Thus, it would provide vital insight to understand the impact of imperfections in general by considering other loading positions, since channel sections are expected to experience eccentric loading in real life, due to the position of their shear centre.

\section{GLOSSARY}

LTB: Lateral-torsional buckling; FEA: Finite element analysis; Al: Aluminium; 3D: Three-dimensional; CAE: Computeraided engineering.

\section{ACKNOWLEDGEMENT}

The Vaal University of Technology supports this research work. The authors want to thank the Department of Mechanical Engineering at the Vaal University of Technology for facilitating this work.

\section{FUNDING}

This research was funded by the NRF Block grant under the guidance of the Vaal University of Technology.

\section{AVAILABILITY OF DATA AND MATERIAL}

All cited articles in this review article are available upon request.

\section{AUTHORS' CONTRIBUTIONS}

All authors jointly contributed to the development of this journal article.

\section{COMPETING INTERESTS}

The authors declare that they have no competing interests. 
International Journal of Engineering Research and Technology. ISSN 0974-3154, Volume 13, Number 9 (2020), pp. 2239-2254

(C) International Research Publication House. https://dx.doi.org/10.37624/IJERT/13.9.2020.2239-2254

\section{REFERENCE}

Dahmani, L. and Drizi, S. (2015) 'Lateral torsional buckling of an eccentrically loaded channel section beam', Strength of Materials, 47(6), pp. 912-916. doi: 10.1007/s11223-015-9728-X.

Efthymiou, E., Cöcen, O. N. and Ermolli, S. R. (2010) 'Sustainable aluminium systems', Sustainability, 2(9), pp. 3100-3109. doi: 10.3390/su2093100.

Guo, Y. et al. (2015) 'An experimental study on out-of-plane inelastic buckling strength of fixed steel arches', Engineering Structures. Elsevier Ltd, 98(9), pp. 118127. doi: 10.1016/j.engstruct.2015.04.029.

Hulamin Extrusions (2015) 'Standard Profile Catalogue'.

Kim, M.-Y., Min, B.-C. and Suh, M.-W. (2000) 'Spatial stability of nonsymmetric thin-walled curved beams. I: Analytical approach', Journal of engineering mechanics, 126(5), pp. 497-505.

Liu, A. et al. (2017) 'Lateral-torsional buckling of fixed circular arches having a thin-walled section under a central concentrated load', Thin-Walled Structures. Elsevier Ltd, 118(May), pp. 46-55. doi: 10.1016/j.tws.2017.05.002.

Mazzolani, F. M. (2004) Design of Aluminium Structures. Naples.

Metals, A. A. S. (2012) 'Aluminum 6061-T6 ; 6061-T651', ASM material data sheet. Florida, USA, pp. 7-8.

Pi, Y. L. and Bradford, M. A. (2003) 'Elasto-plastic buckling and postbuckling of arches subjected to a central load', Computers and Structures, 81(18-19), pp. 1811-1825. doi: 10.1016/S0045-7949(03)00204-9.

Pi, Y. L. and Bradford, M. A. (2005) 'Out-of-plane Strength Design of Fixed Steel I-Section Arches', Engineering Structures, 131(4), pp. 560-568. doi: 10.1016/j.engstruct.2003.09.011.

Pi, Y. L., Bradford, M. A. and Tong, G. S. (2010) 'Elastic lateral-torsional buckling of circular arches subjected to a central concentrated load', International Journal of Mechanical Sciences. Elsevier, 52(6), pp. 847-862. doi: 10.1016/j.ijmecsci.2010.02.003.

Pi, Y. L. and Trahair, N. S. (2000) 'Inelastic lateral buckling strength and design of steel arches', Engineering Structures, 22(8), pp. 993-1005. doi: 10.1016/S01410296(99)00032-2.

La Poutré, D. B. (2005) Inelastic spatial stability of circular wide flange steel arches. doi: 10.6100/IR585818.

La Poutré, D. B. et al. (2013) 'Out-of-plane stability of roller bent steel arches - An experimental investigation', Journal of Constructional Steel Research. Elsevier Ltd,
81(5), pp. 20-34. doi: 10.1016/j.jcsr.2012.11.004.

Sadowski, A. J., Fajuyitan, O. K. and Wang, J. (2017) 'A computational strategy to establish algebraic parameters for the Reference Resistance Design of metal shell structures', Advances in Engineering Software. Elsevier Ltd, 109, pp. 15-30. doi: 10.1016/j.advengsoft.2017.02.012.

Snijder, H. H. et al. (2008) 'Design rules for lateral torsional buckling of channel sections subject to web loading', Stahlbau, 77(4), pp. 247-256. doi: 10.1002/stab.200810036.

Spoorenberg, R. C. (2011) Structural properties and out-ofplane stability of roller bent steel arches. doi: 10.6100/IR716581.

Spoorenberg, R. C. et al. (2012) 'Design rules for out-ofplane stability of roller bent steel arches with FEM', Journal of Constructional Steel Research, 79, pp. 9-21. doi: 10.1016/j.jcsr.2012.07.027.

Tebo, E. T., Masu, L. and Nziu, P. (2020) 'Effects of Factors That Influence Out-of-Plane Lateral-Torsional Buckling on Freestanding Circular Arches', Journal of Engineering, 2020, pp. 1-12. doi: $10.1155 / 2020 / 4892070$.

Valeš, J. and Stan, T. (2017) 'FEM Modelling of LateralTorsional Buckling using Shell and Solid Elements'. Elsevier BV, 190, pp. 464-471. doi: 10.1016/j.proeng.2017.05.365.

Wang, Y. Q. et al. (2012) 'Lateral-torsional buckling resistance of aluminium I-beams', Thin-Walled Structures. Elsevier, 50(1), pp. 24-36. doi: 10.1016/j.tws.2011.07.005.

Wesley, D. (2017) Lateral-torsional Buckling of Steel Channel Beams A parametric study through FEanalysis. 